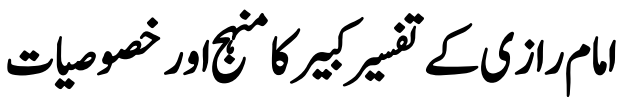

\title{
The academic characteristics and style of the "Tafseer-e- Kabeer" Imam Razi.
}

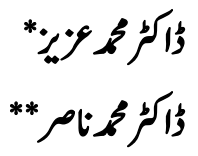

\begin{abstract}
Imam Razi has earned a reliable name and fame in world of scholars. He was the great exponent of Islam and his famous and unique interpretive work on the Quran called "Tafseer Kabeer" is considered as remarkable and valuable work in the Muslim world. Originally it was named "Mafatih Al-Ghayb" however it was nicknamed as Tafsir Al-Kabir. Being a great research work, power of an argumentation and prudenciality, it is an incomparable Tafseer. Imam Razi was well versed, both in rationality and traditional religion. This commentary contains much of philosophical and intellectual interest. The nature of this commentary is big different from others in many way. Hehas explained, grammatical composition, and background of revelation with clarity and detail.It contains a strong refutation of all the erring sects of his time, namely, Jahmiyyah, Mu'tazilah, Mujassimah, etc..The purpose of this research is to describe the methodology and techniques of Tafseer-e-Kabeer.
\end{abstract}

Key Words: Tafseer-e-Kabeer, Rationality, Theologian, Mu'tazilah.

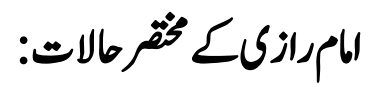

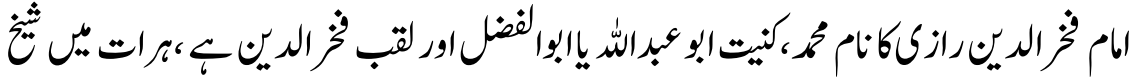

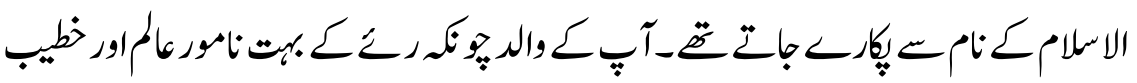

$$
\begin{aligned}
& 1 \text { 1 }
\end{aligned}
$$

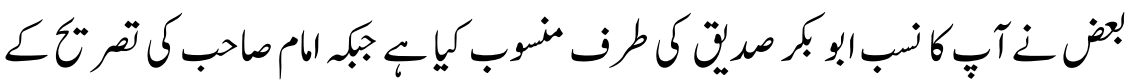

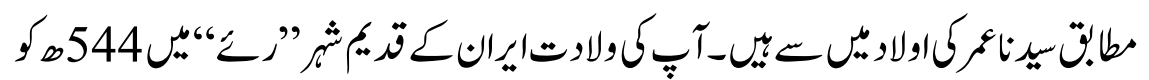

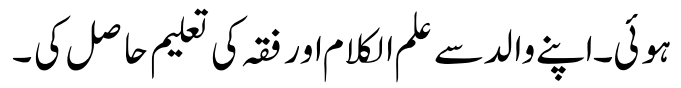

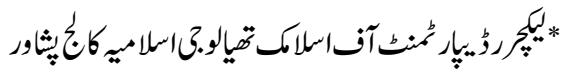

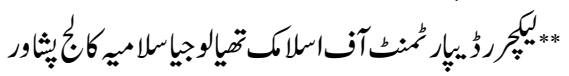




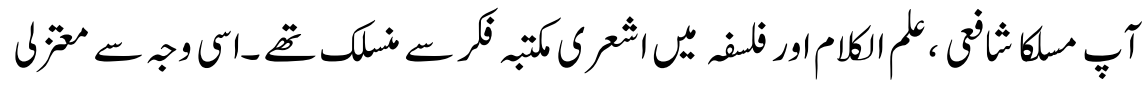

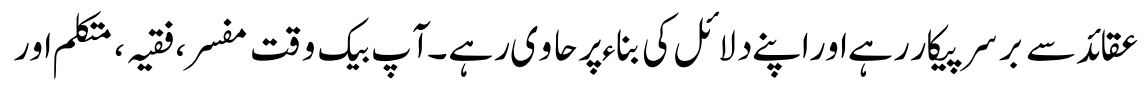

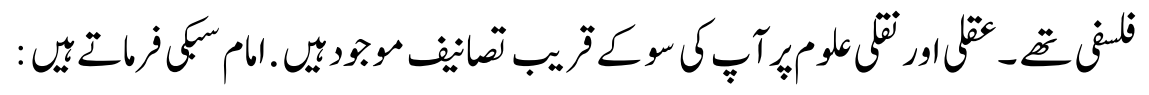

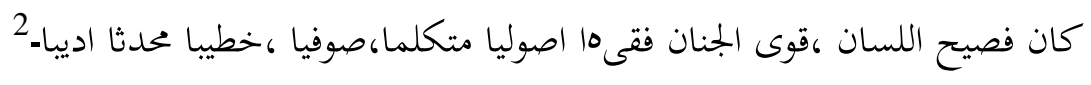

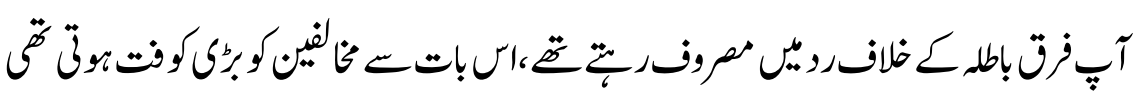

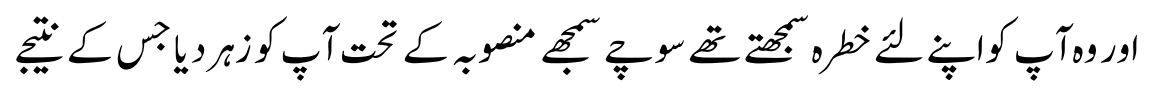

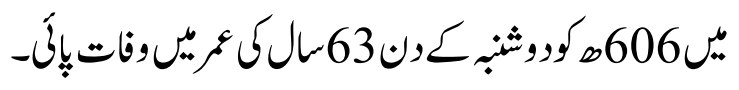

تيركيركاتحارف:

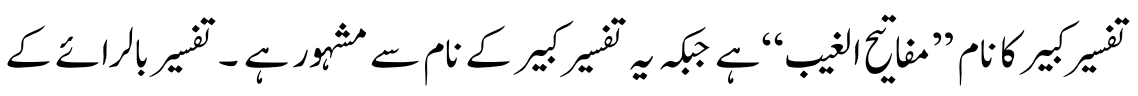

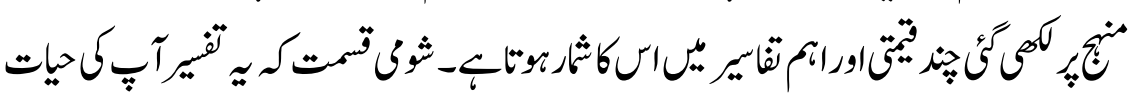

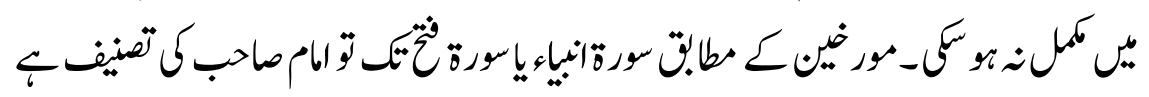

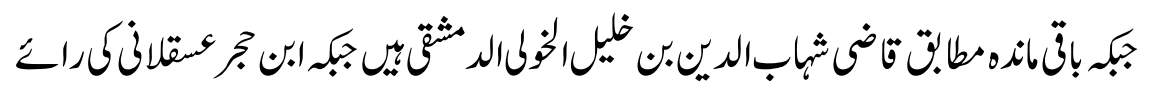

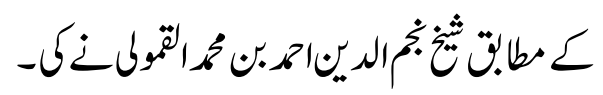

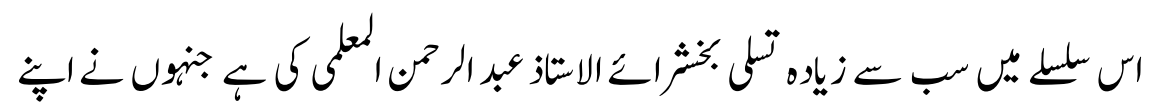

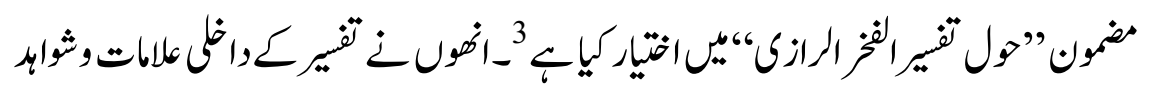

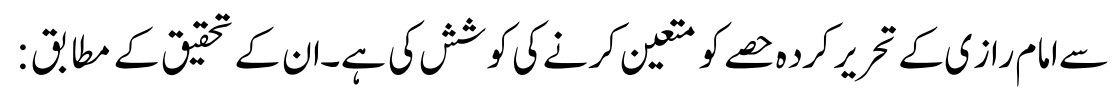

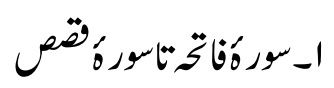

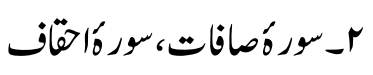

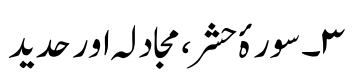

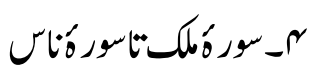

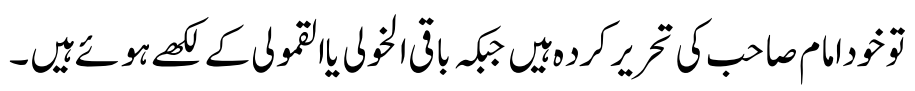




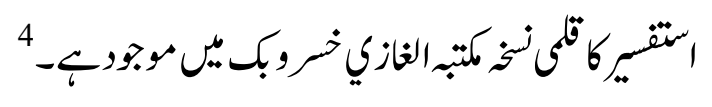

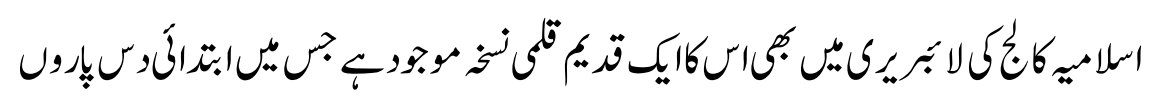

$$
\begin{aligned}
& \text { كم تنير مو.وربك- } \\
& \text { امرازك6 منج تضم }
\end{aligned}
$$

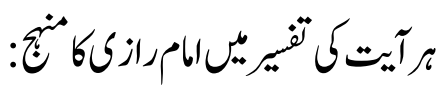

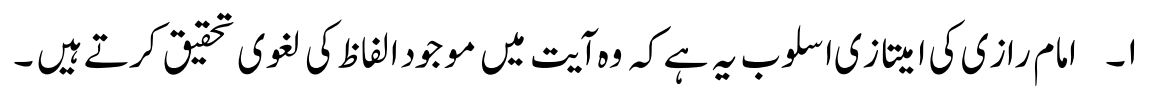

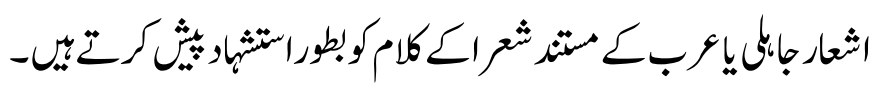

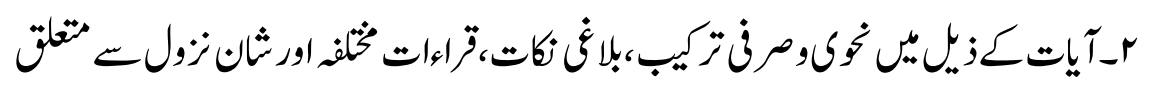

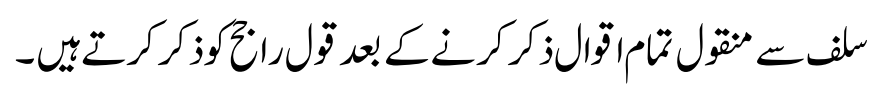

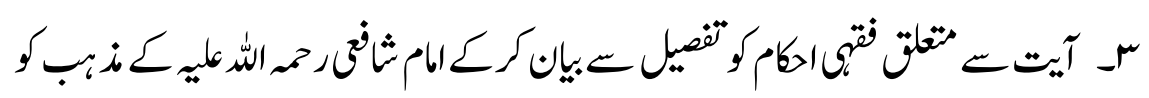

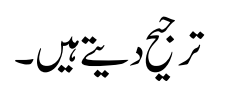

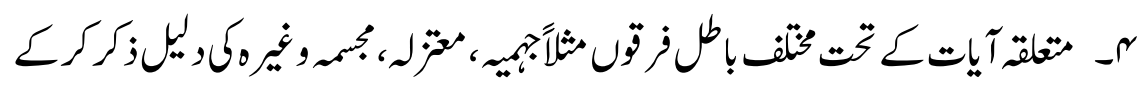

$$
\text { اسكترويمكرت بيك- }
$$

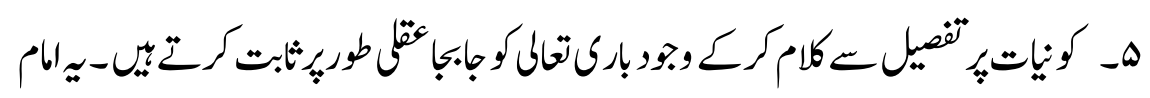

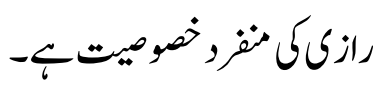

$$
\begin{aligned}
& \text { ثفيرك خصوصيات: }
\end{aligned}
$$

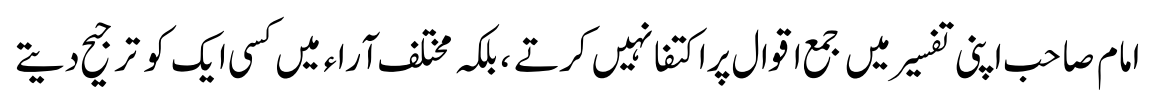

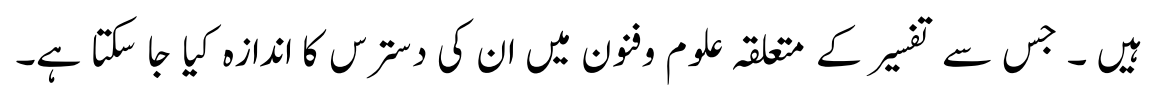

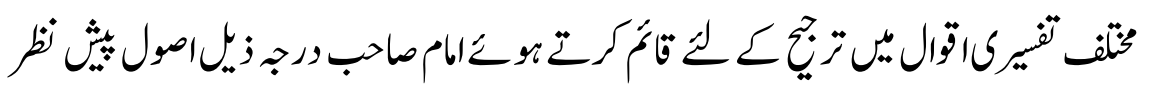
ركمّتب. 


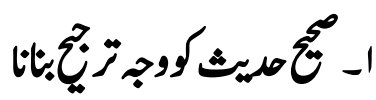

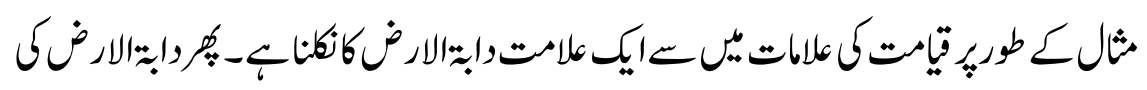

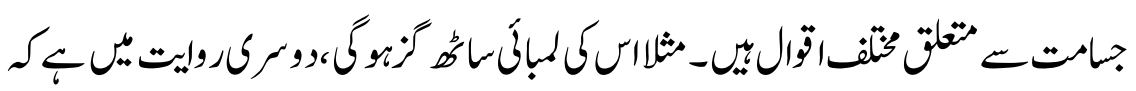

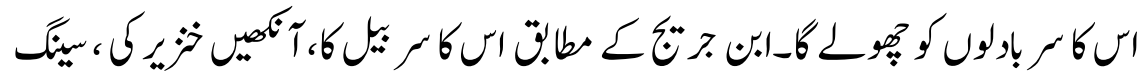

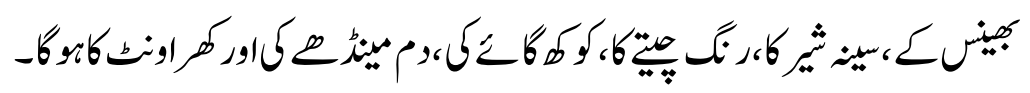

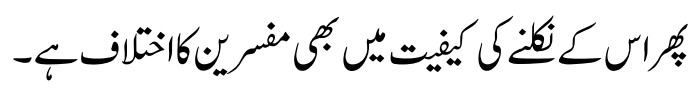

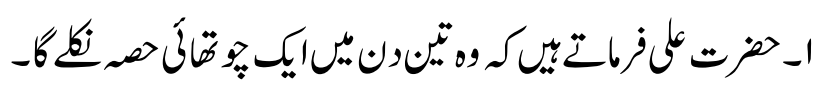

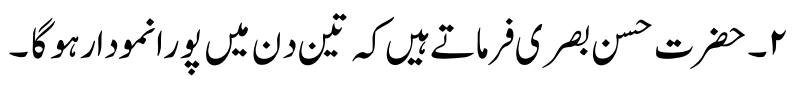

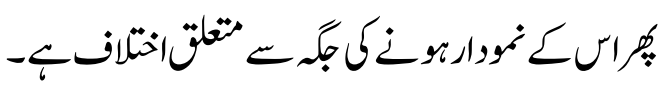

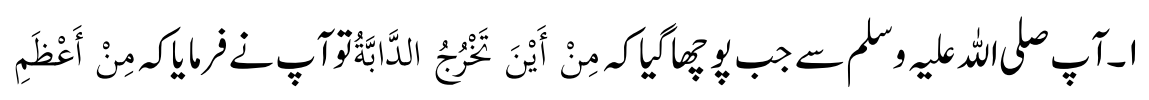
الْمَسَاِِدِ

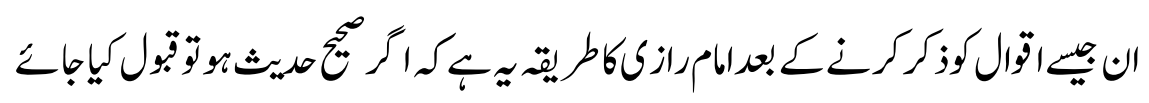

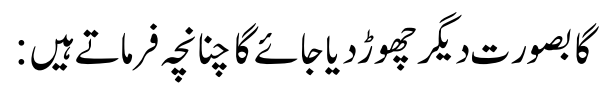

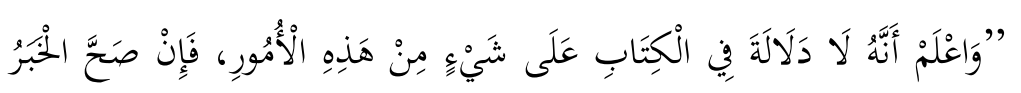

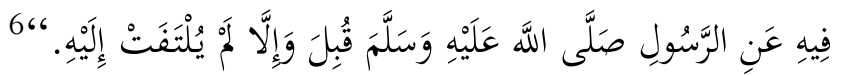

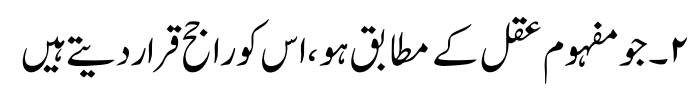

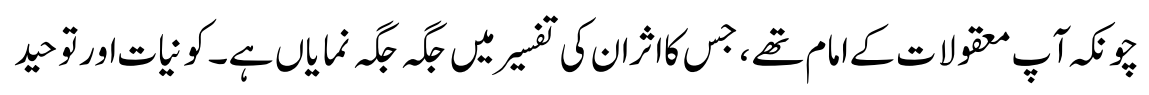

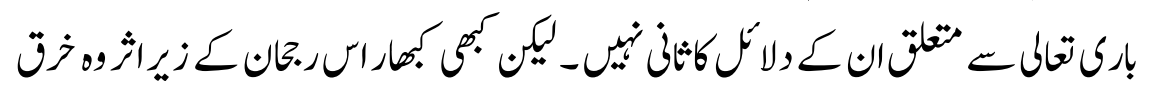

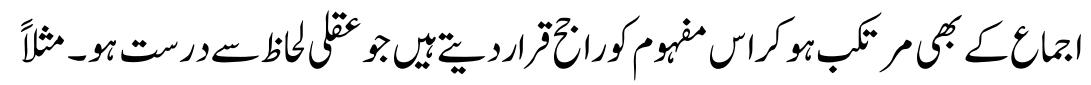




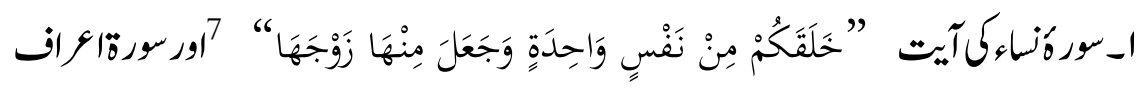

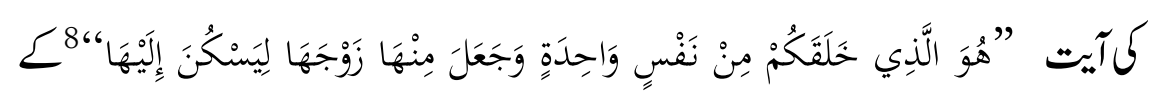

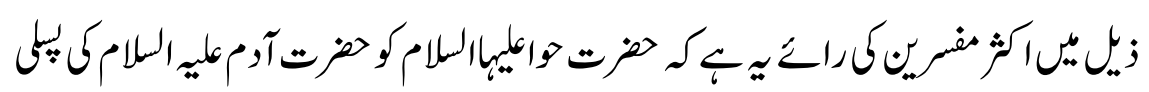

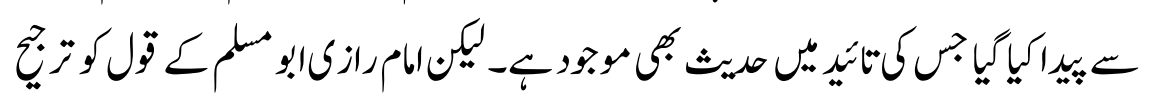

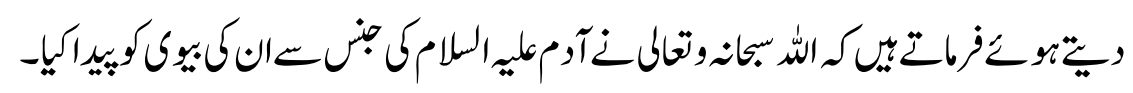

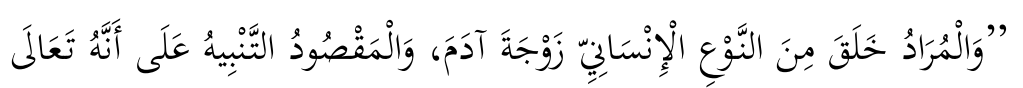

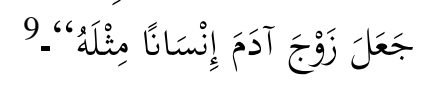

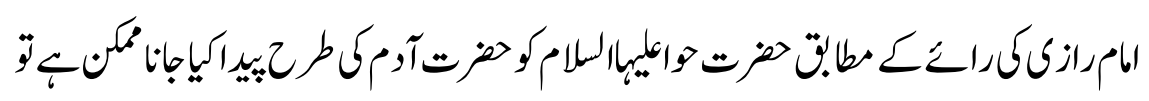

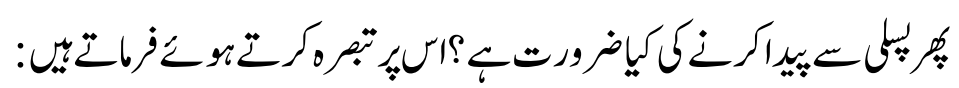

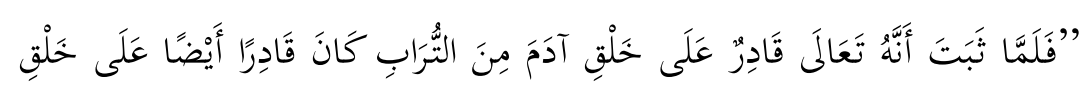

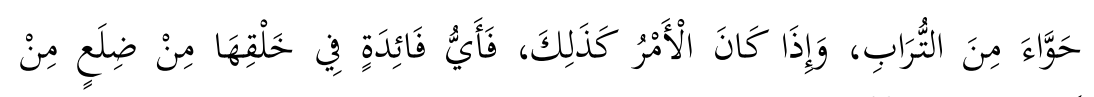

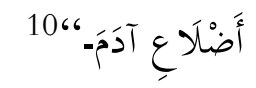

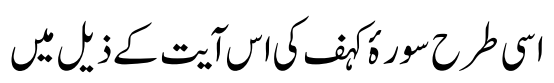

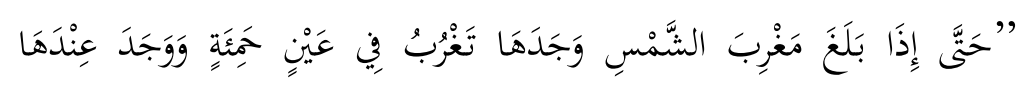
قَوْمَا." 11

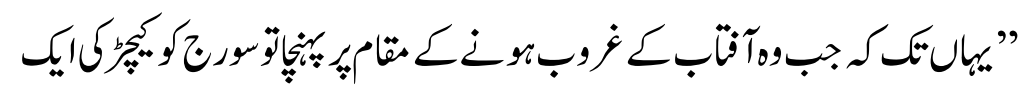

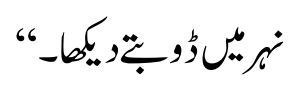

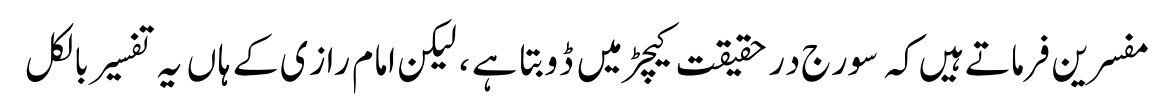

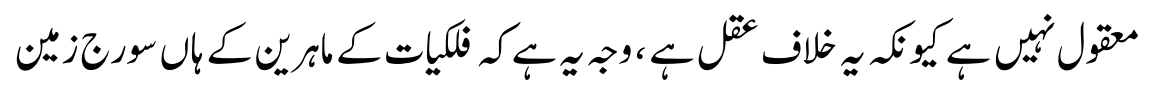

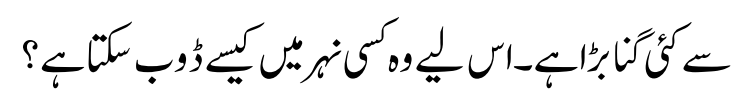

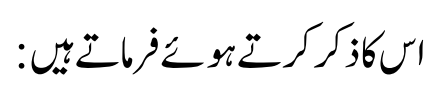




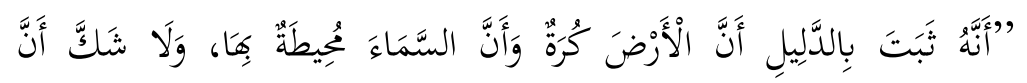

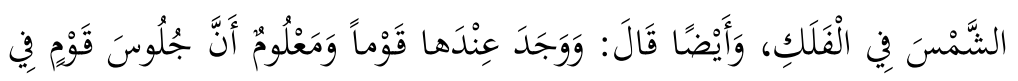

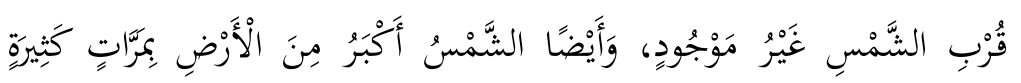

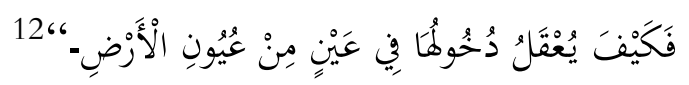

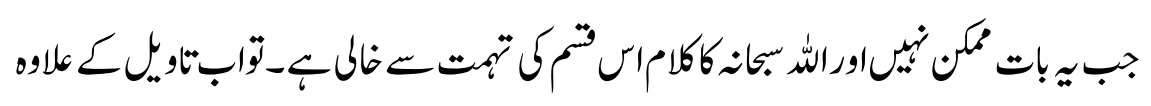

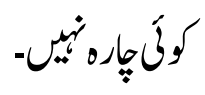

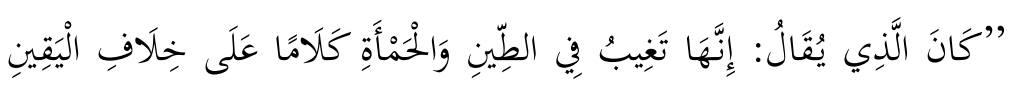

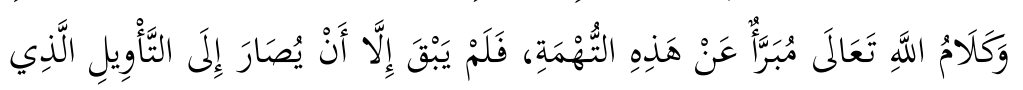
ذكرناه-13،

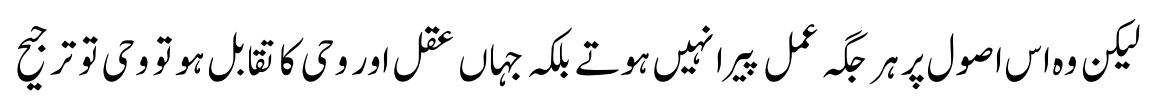

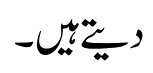

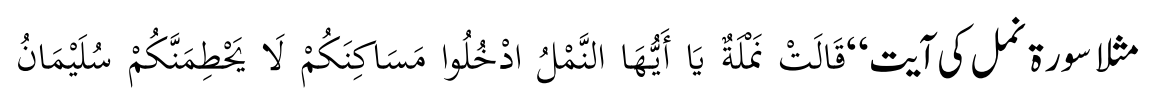

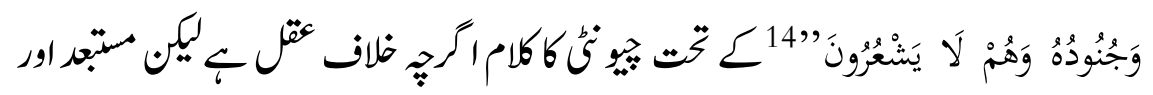

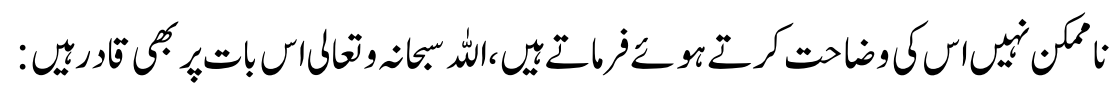

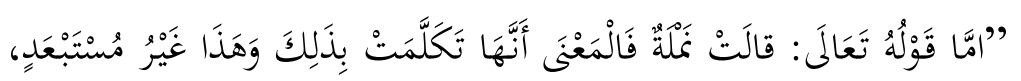

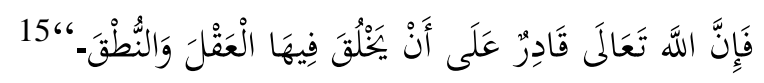

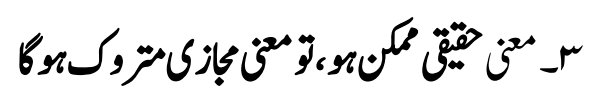

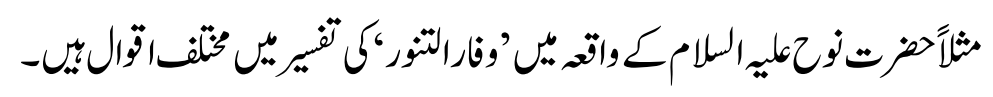

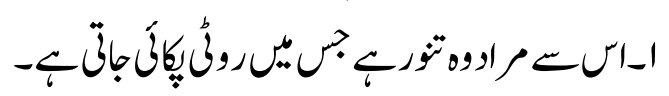

$$
\begin{aligned}
& \text { r }
\end{aligned}
$$

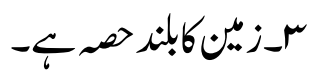

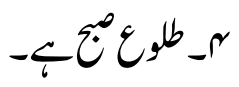




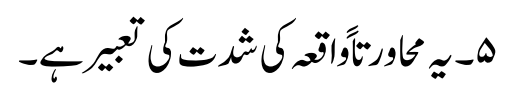

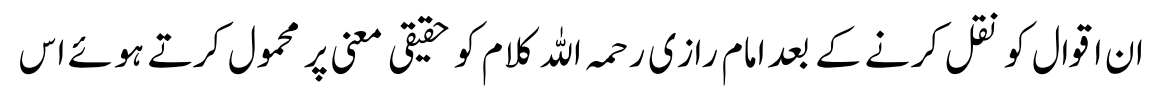

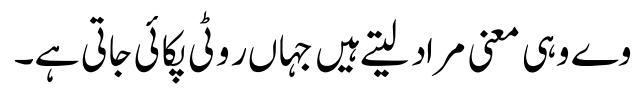

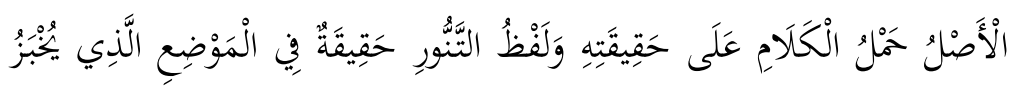

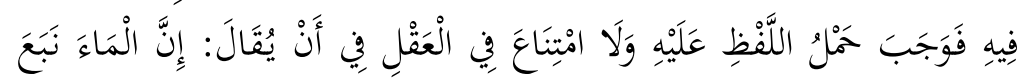

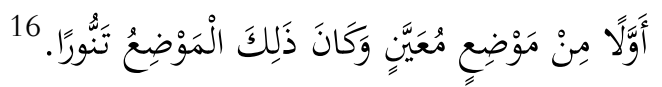

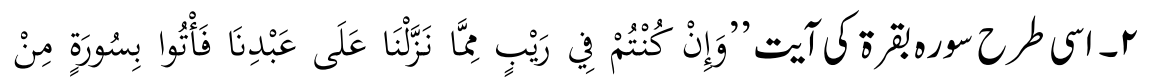

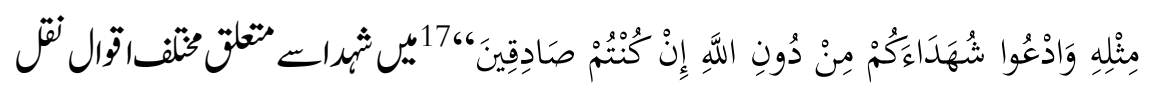

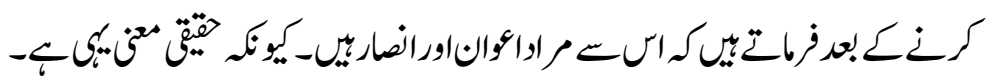

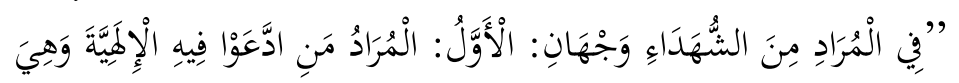

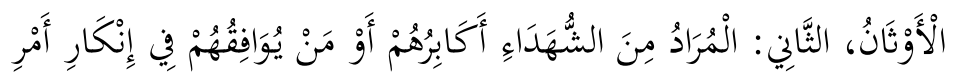

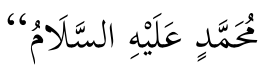

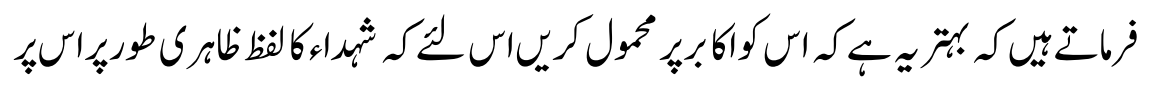

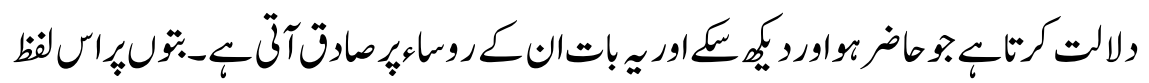

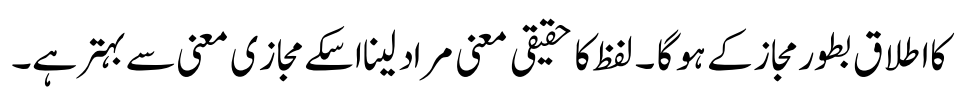

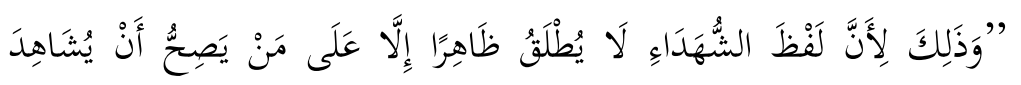

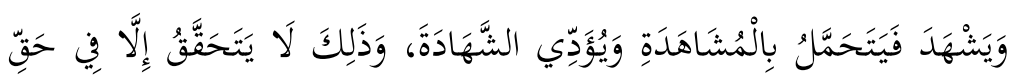

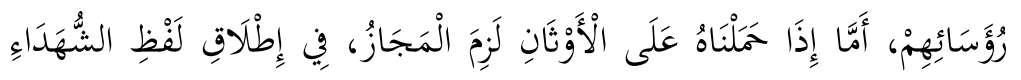

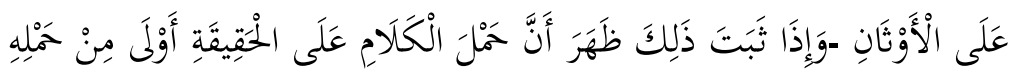

$$
\text { عَلَى الْمَجَازِ. }
$$

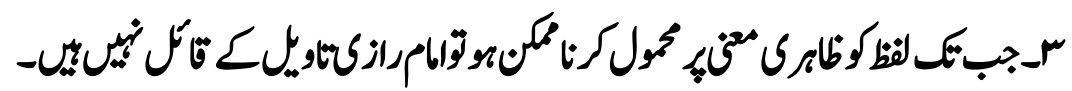

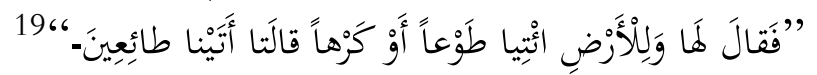

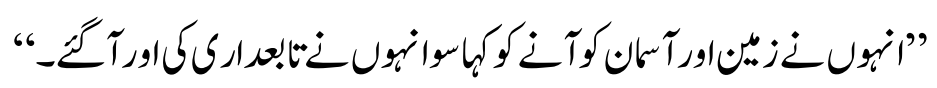




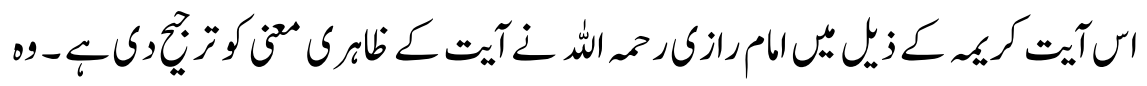

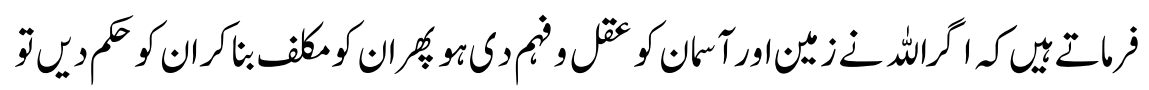

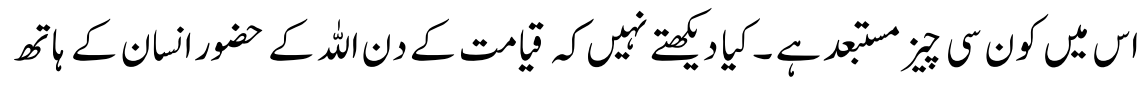

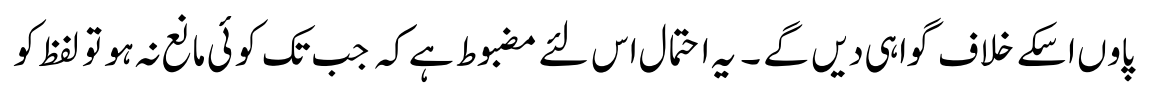

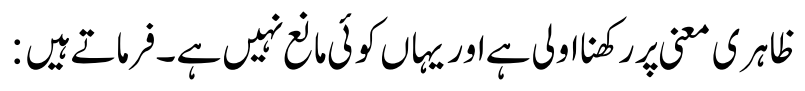

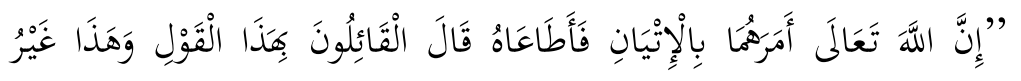

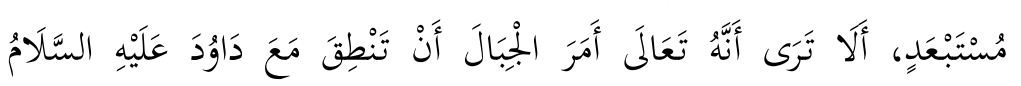

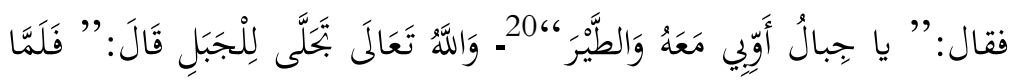

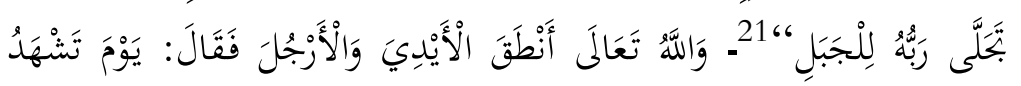

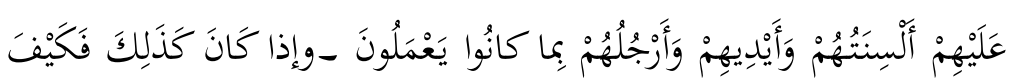

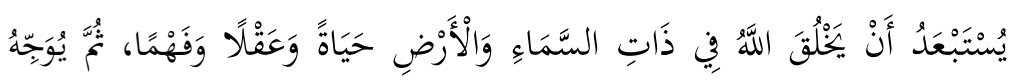

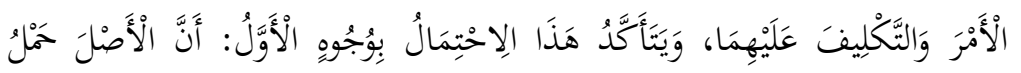

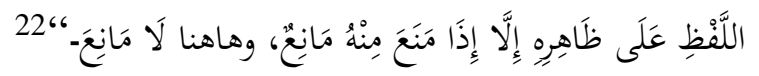

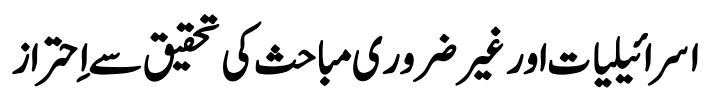

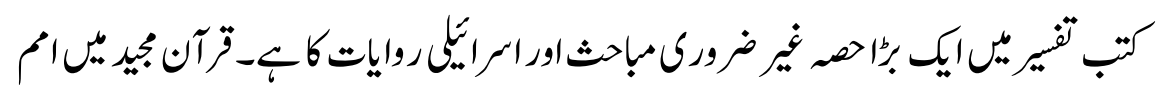

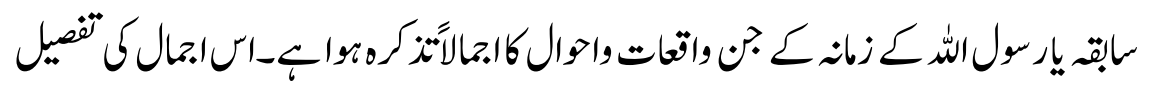

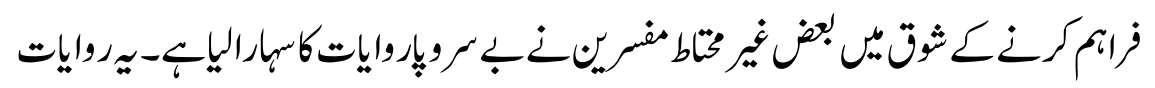

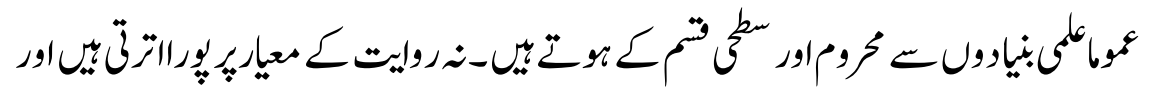

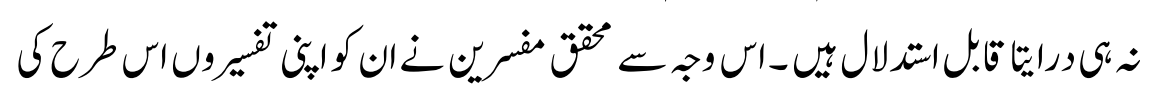

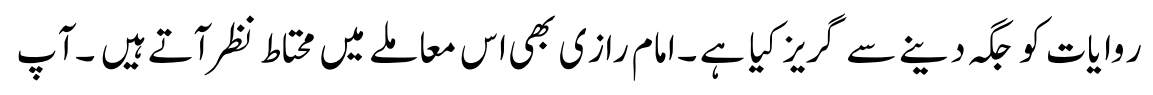

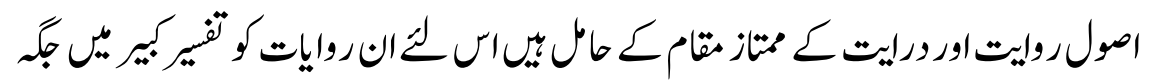
"ن

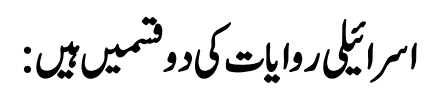




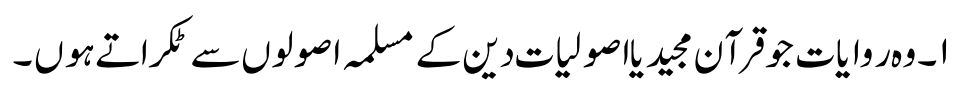

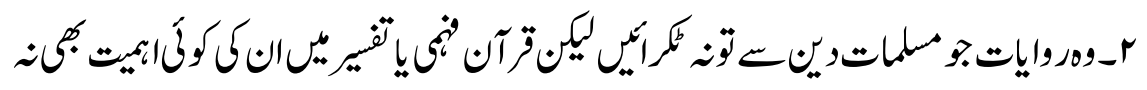
$-U$

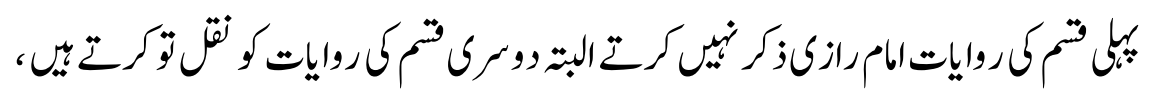

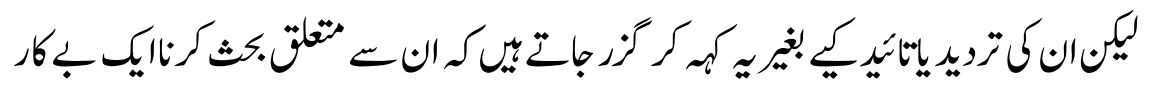

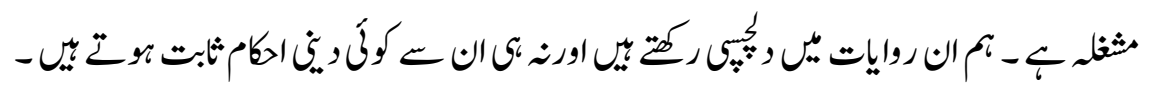

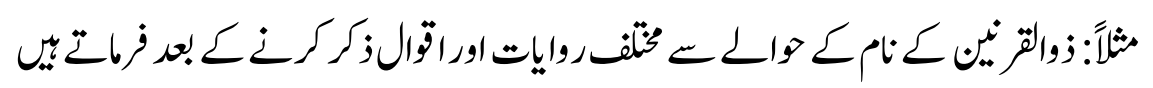

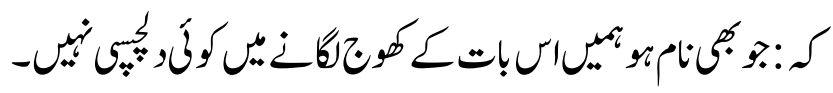

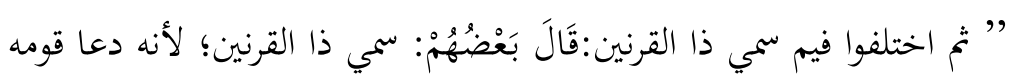
إلى توحيد اللَّ والإيمان به؛ فضربوه على قرنه الأيمن، ثم غاب ما ما شاء اللَّه، وفي بعض الأخبار مات، ثم حضر فدعاهم ثانيًا فضربوه على قرنه الأيسر؛ فبقي

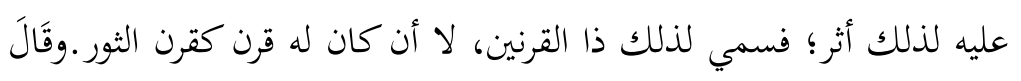

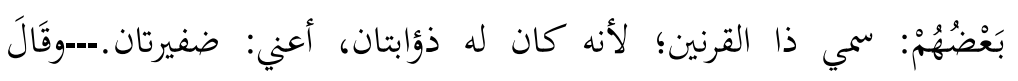

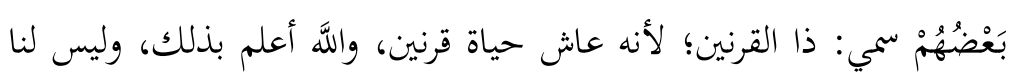
إلى معرفة ذلك حاجة.

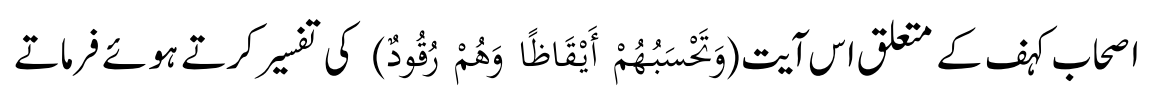

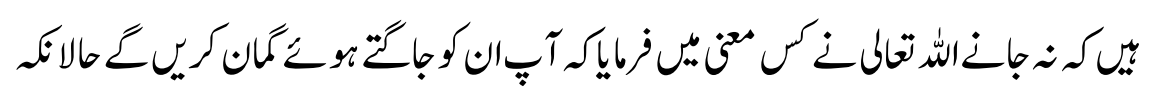

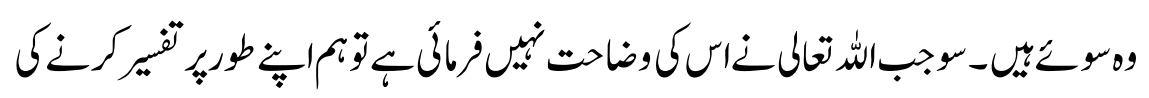
جارت "نيّ كرت _" ولكن لا ندري لأي معنى ذكر أنه يحسب الناظر إليهم كأغم

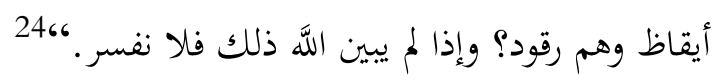

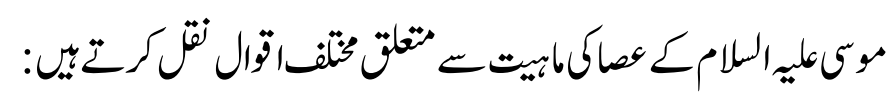

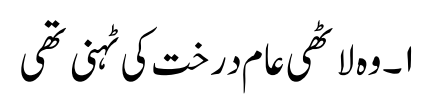




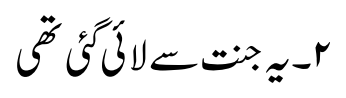

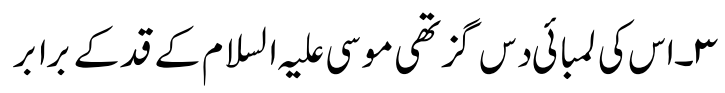

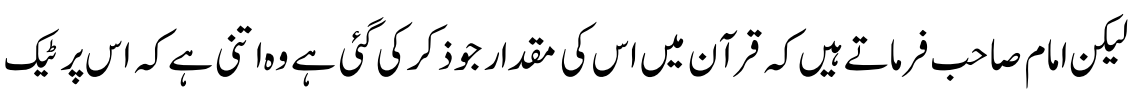

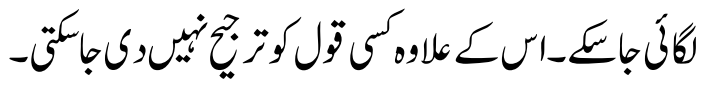

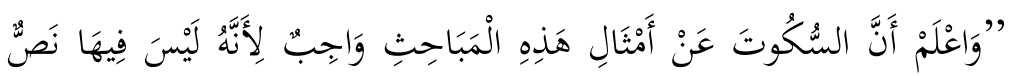

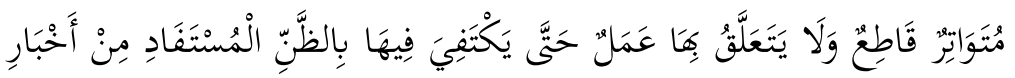

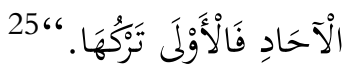

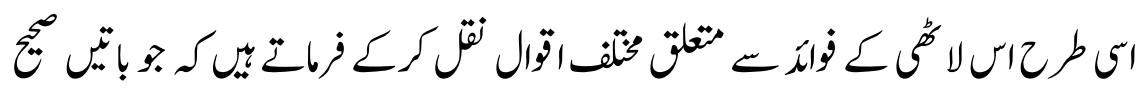

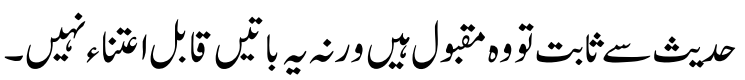

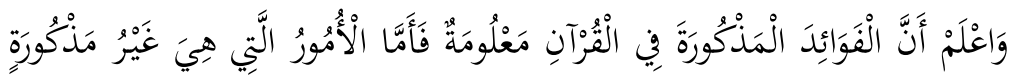

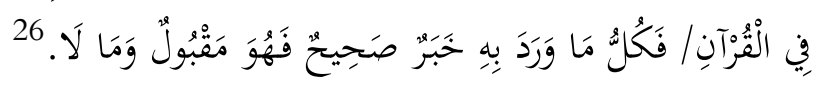

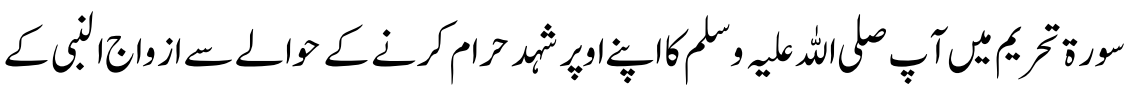

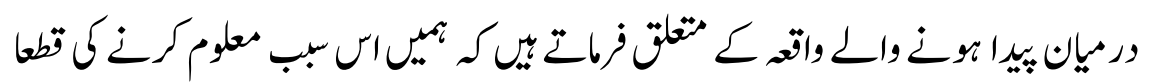

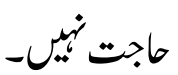

ومنهم من قال: إن الذي حرمه النبيصَلَّى اللَّهُ عَلَيهِ وَسَلَّمَ كان عسلا، كان

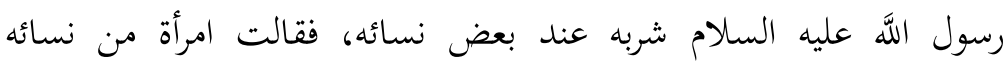

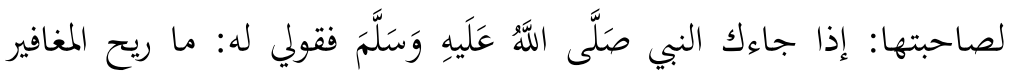
فيك؟ فقالت للنبي؛ فحرمه النبي عليه السلام فنزلت هذه الآية. اسك بعرفاكتيك: 
وليس لنا إلى تعرف السبب الذي وقع التحريم به، ولا إلى تعيين الشيء الذي

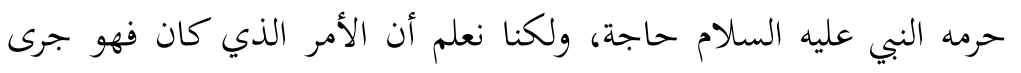
بينه وبين زوجاته- 27

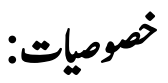

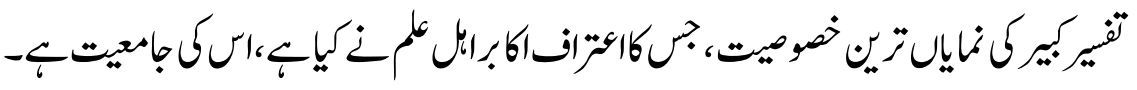

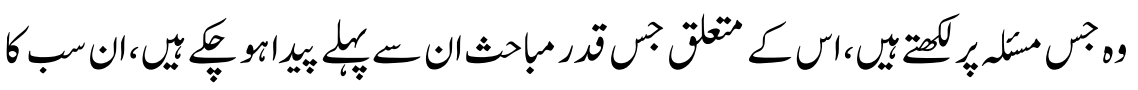

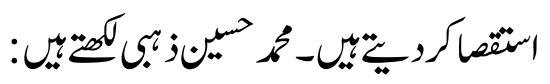

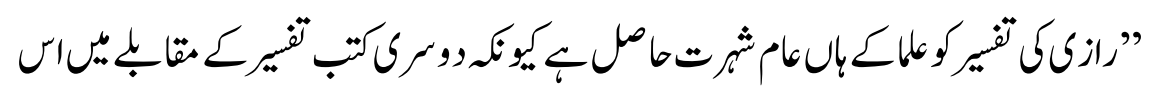

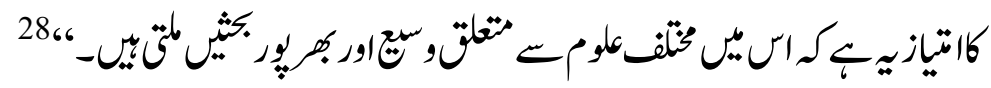
نقائُ:

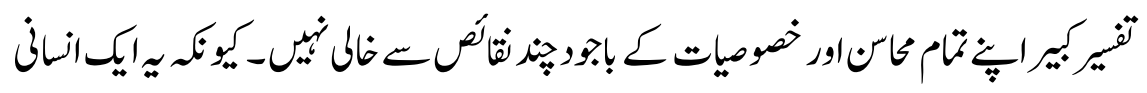

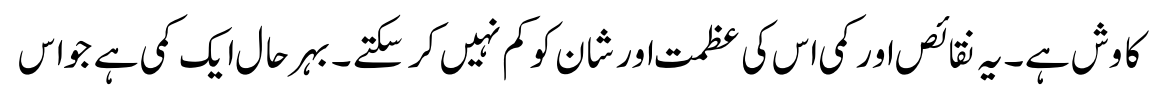

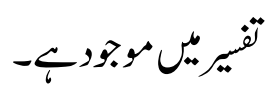

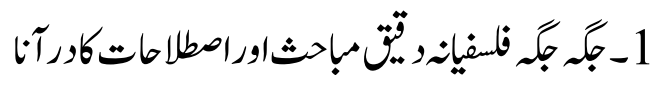

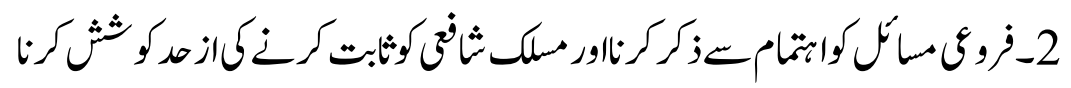

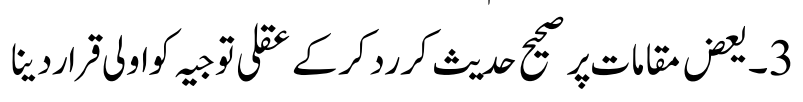

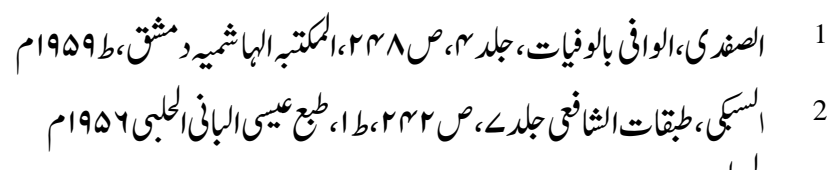
3 


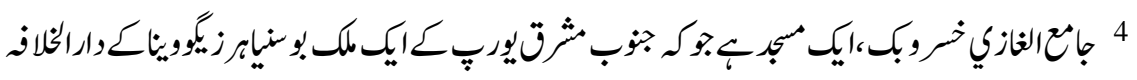

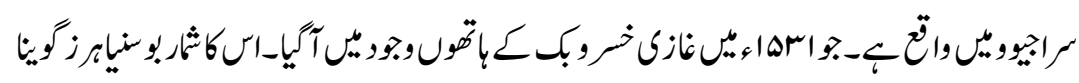

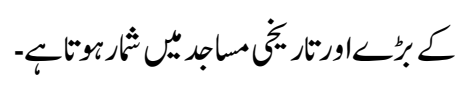

/http://www.alukah.net/library/0/76069:" يكيمً

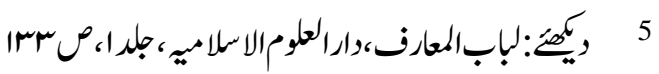

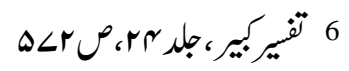

$$
\begin{aligned}
& 7 \\
& 8
\end{aligned}
$$

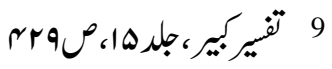

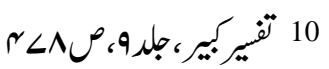

$$
\begin{aligned}
& 11 \text { 11 الكبف11 } \\
& 12 \text { تنيركير،جلدابوص } 13
\end{aligned}
$$

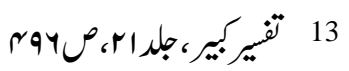

$$
\begin{aligned}
& 14
\end{aligned}
$$

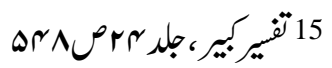

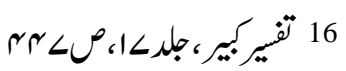

$$
\begin{aligned}
& 17 \text { البقة } 18
\end{aligned}
$$

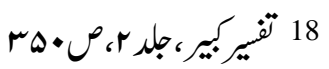

$$
\begin{aligned}
& 19 \text { نصلت:اr/| } \\
& 20 \\
& 21 \text { الأ افتسم| }
\end{aligned}
$$

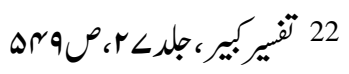

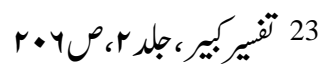

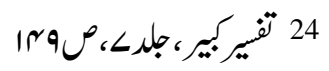

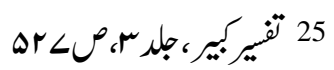




$$
\begin{aligned}
& 26 \text { تفيركيم، جلرس، }
\end{aligned}
$$

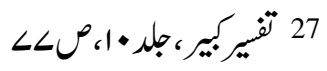

$$
\begin{aligned}
& 28 \text { الثير والمفر ون، آهن }
\end{aligned}
$$

